\title{
Expression of proliferating cell nuclear antigen in luminal epithelium during the growth and regression of rat uterus
}

\author{
M-D Lai, L-R Lee, K-S Cheng ${ }^{1}$ and L-Y C Wing \\ Department of Physiology, College of Medicine, National Cheng Kung University, Tainan, Taiwan \\ ${ }^{1}$ Institute of Biomedical Engineering, National Cheng Kung University, Tainan, Taiwan \\ (Requests for offprints should be addressed to L-Y C Wing; Email: wing@mail.ncku.edu.tw)
}

\begin{abstract}
Proliferating cell nuclear antigen (PCNA), a processivity factor of DNA synthesis, has often been used as a marker that reveals proliferating cells. However, it also plays a role other than in DNA replication. The aim of this study was to examine the relationship between the expression of PCNA and cell proliferation, and also its relation to cell death in the uterine epithelium under various hormonal conditions. Rats with regular estrous cycles were killed at various stages of the cycle, and their uteri were removed for the detection of PCNA and apoptosis by immunohistochemical and terminal deoxynucleotidyl transferasemediated nick end-label staining respectively. There was an inverse relationship between the expression of PCNA and apoptosis in the uterine epithelium during the estrous cycle. From diestrus to proestrus, the expression of PCNA increased, and few apoptotic cells were detected in the luminal epithelium. However, at estrus, apoptosis occurred markedly, and the expression of PCNA disap-
\end{abstract}

peared. To study further the effects of estrogen on PCNA expression and cell growth in the uterus, rats were ovariectomized and then implanted s.c. with estrogen capsules 2 weeks later. In ovariectomized rats, only a few PCNA-positive cells were observed in the uterine epithelium. After estrogen treatment, PCNA was expressed strongly in the luminal and glandular epithelia. In these rats, the removal of estrogen capsules resulted in apoptotic death and surprisingly strong PCNA expression in the cells of luminal epithelium. Our results demonstrate that PCNA is expressed not only in the estrogen-stimulated uterine growth, but also in the processes of regression induced by the withdrawal of estrogen. Although the expression of PCNA has been reported to represent cell proliferation, our results implicate functions other than cell replication for PCNA in the uterus.

Journal of Endocrinology (2000) 166, 87-93

\section{Introduction}

Tritiated thymidine or bromodeoxyuridine (BrdU), a thymidine analog that labels cells undergoing DNA synthesis, is often used as a marker of cell proliferation. However, dependence on the use of radioisotope and the administration of exogenous substance to an in vivo system have somewhat limited their application. Recently, proliferating cell nuclear antigen (PCNA) has been used to identify replicating cells. PCNA fucntions as a processivity factor of polymerase $\delta$ and $\varepsilon$ and is essential for DNA replication (Kelman 1997, Tasurimoto 1998). The detection of PCNA in animal studies has provided results that are comparable to those achieved with quantitative analysis using tritiated thymidine (Eldridge et al. 1993, Foley et al. 1993, Li 1994). These results suggest that PCNA can serve as an endogenous marker of cell proliferation. In addition to its role in DNA replication, PCNA is also involved in DNA repair. The overexpression of PCNA without accompanying cell proliferation was observed in cells after u.v. irradiation-induced DNA damage (Celis \& Madsen 1986, Toschi \& Bravo 1988, Nichols \& Sancar 1992). PCNA was also expressed during tissue regression, such as in the corpus luteum during structural luteolysis, the prostate gland after castration and the neural apoptosis after dopamine stimulation (Colombel et al. 1992, Kiya et al. 1998, Shirvan et al. 1997). Furthermore, recent studies have suggested that PCNA can act as a docking site to interact with numerous proteins that are involved in cell cycle regulation and DNA repair (Kelman \& Hurwitz 1998, Tasurimoto 1998). Thus the interaction of PCNA with other proteins that have various cellular activities suggests that PCNA may have multifunctional roles in addition to DNA replication.

The uterus, which undergoes growth and regression under the regulation of ovarian hormones, is a good model with which to evaluate the role of PCNA in cell proliferation and cell death. Animal studies have shown that the administration of estrogen stimulates the proliferation of uterine epithelial cells and that the withdrawal of estrogen 


\section{PCNA}
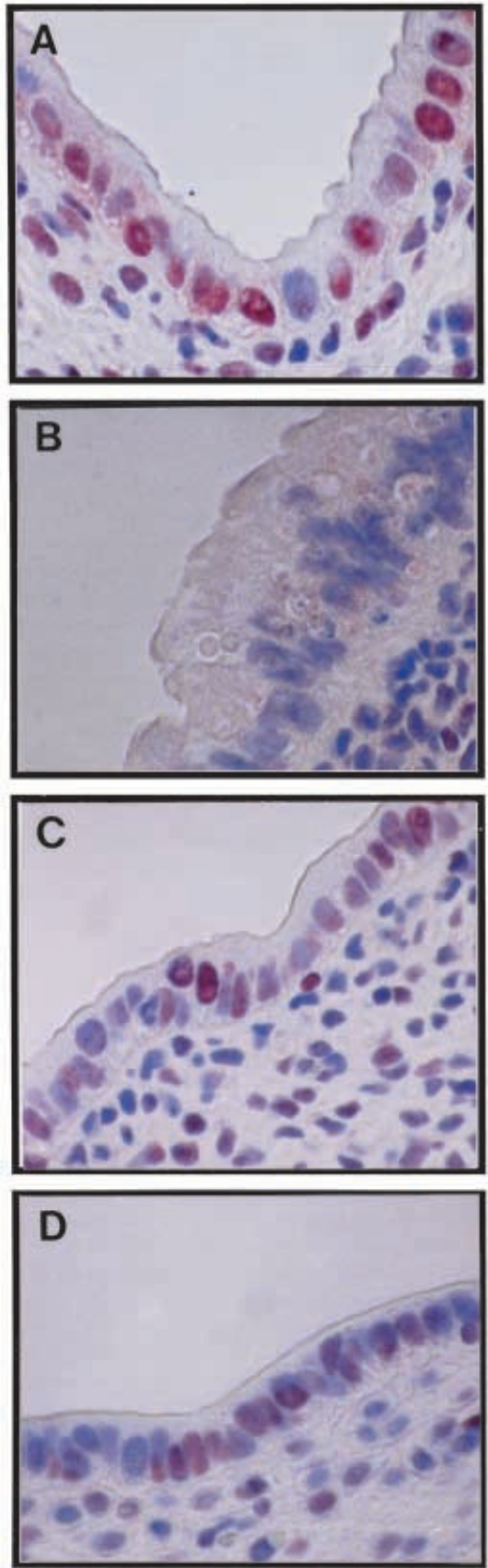

Figure 1 PCNA expression and apoptosis in the uterine luminal epithelium during the estrous cycle. Rats were killed at proestrus (A, E), estrus (B, F), diestrus I (C, G) and diestrus II $(\mathrm{D}, \mathrm{H})$. Their uteri were removed for immunostaining of PCNA (A-D) and detection of apoptotic cells by TUNEL $(E-H)$. Arrowheads indicate apoptotic cells. Scale bar represents $100 \mathrm{~mm}$.

\section{TUNEL}
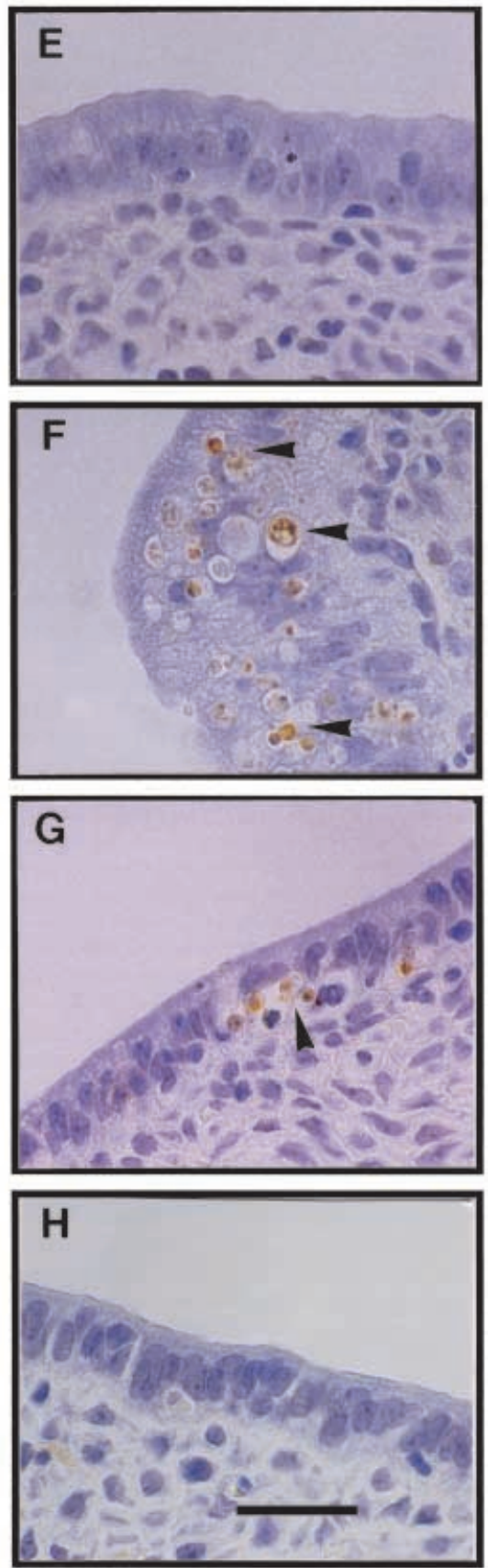

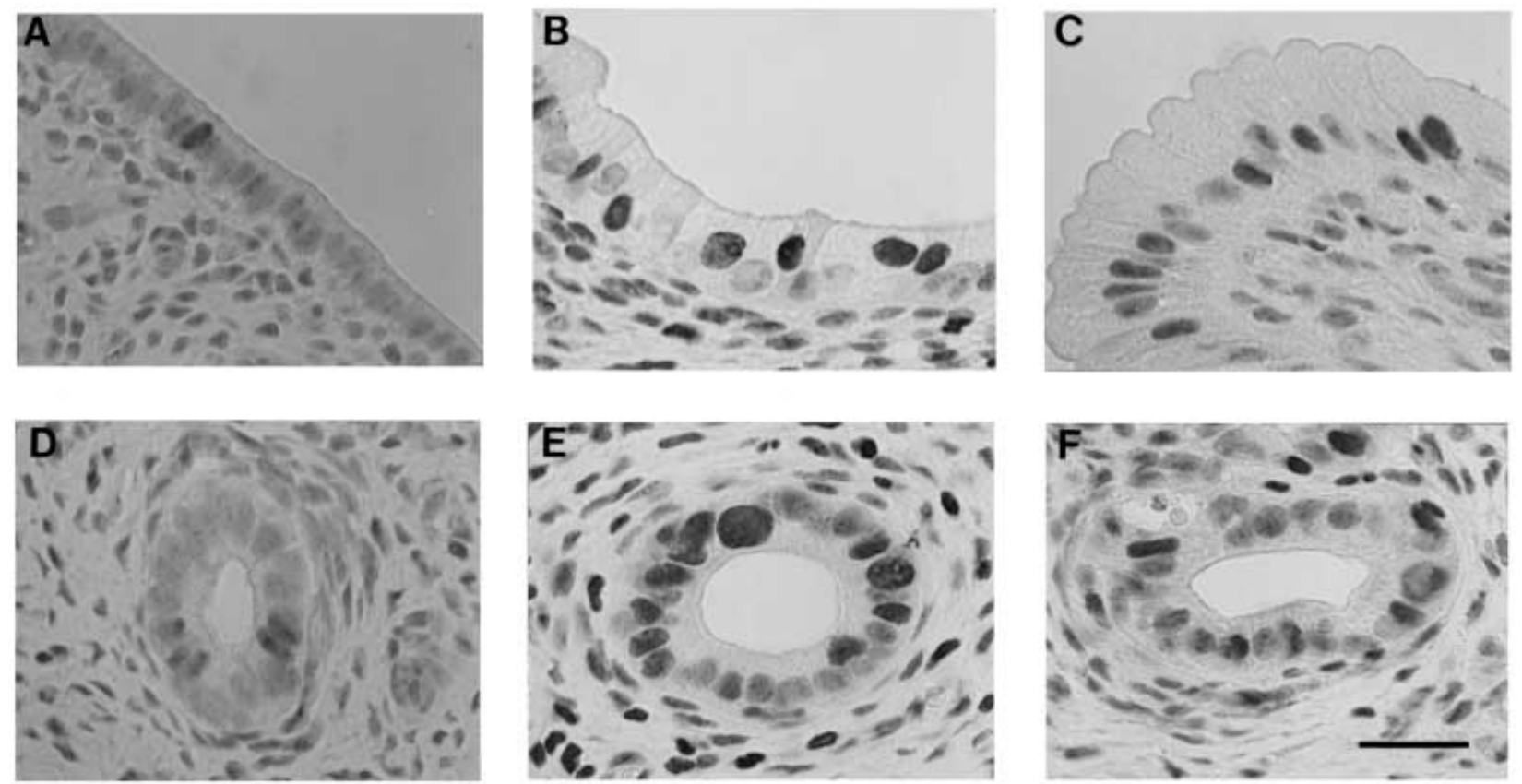

Figure 2 Immunostaining of PCNA in uterine luminal (A-C) and glandular (D-F) epithelium of estrogen-treated rats. Animals were ovariectomized for 2 weeks and then implanted with $\mathrm{E}_{2}$ capsules for 1 or 3 days. A, D: ovariectomy; $\mathrm{B}, \mathrm{E}: 1$ day after $\mathrm{E}_{2}$ treatment; $\mathrm{C}$, F: 3 days after $E_{2}$ treatment. Scale bar represents $100 \mathrm{~mm}$.

results in apoptotic death (Martin et al. 1976, Finn \& Publicover 1984, Quarmy \& Korach 1984). In the present study, we have investigated the expression of PCNA during the estrous cycle and in ovariectomized rats after estrogen treatment and withdrawal. Our results indicate that PCNA is expressed not only during growth but also during the regression of the uterine epithelium.

\section{Materials and Methods}

\section{Animals}

Wistar female rats, 8-10 weeks old were obtained from the Animal Center at the College of Medicine, National Cheng Kung University. Animals were maintained on standard chow and water, which were available ad libitum, in animal facilities illuminated between 0600 and $1800 \mathrm{~h}$. All procedures were performed in accordance with the Guidelines of the NCKU University Animal Center for the handling and training of laboratory animals in an animal center. The stages of the estrous cycle were confirmed by vaginal smears. Rats with two to three regular cycles were used in these experiments and killed at various stages of the estrous cycle. For the study on hormonal control of the uterus, rats were ovariectomized for at least 2 weeks and then implanted s.c. with silastic capsules containing estradiol $17-\beta\left(\mathrm{E}_{2}\right)$ powder, prepared according to the procedures described by Legan et al.
(1979). After 3 days, $E_{2}$ capsules were removed from some animals, and animals were killed at different time intervals.

\section{Immunohistochemical staining}

The uterus was fixed in $4 \%$ paraformaldehyde solution and embedded in paraffin. Tissue sections $5 \mu \mathrm{m}$ thick were mounted on polylysine-coated slides, deparaffinized, rehydrated, and then heated with $10 \mathrm{mM}$ citrate buffer (pH 6) in a $95^{\circ} \mathrm{C}$ water bath for $15 \mathrm{~min}$. After two washings with PBS, a primary antibody of PCNA (Zymed Lab. Inc., San Francisco, CA, USA, 1:100 dilution) was added to the slides and incubated at $4{ }^{\circ} \mathrm{C}$ overnight. After washing three times, tissue sections were incubated for $1 \mathrm{~h}$ with $3 \mu \mathrm{g} / \mathrm{ml}$ biotinylated goat anti-mouse antibody (Vector Laboratories, Burlingame, CA, USA). The slides were then incubated with $3 \%$ hydrogen peroxide to quench endogenous peroxidase activity. After three washings with PBS, slides were incubated with an avidinbiotin complex reagent containing horseradish peroxidase (Vector Laboratories) in PBS and color development was achieved by incubation using the aminoethyl cabazole substrate kit (Zymed Lab. Inc.). The tissue sections were counterstained with hematoxylin. To determine the percentage of PCNA-positive cells, PCNA-staining cells and non-staining cells in high-powered fields were counted in different areas of luminal epithelium. A 
minimum of 500 cells in different tissue sections per animal specimen were analyzed. The percentage of PCNA-positive cells was calculated (number of PCNApositive cells divided by total number of cells counted multiplied by 100$)$.

\section{Terminal deoxynucleotidyl transferase-mediated nick} end-labeling (TUNEL)

The procedures as described for the TdT fragELTM DNA fragmentation detection kit (Oncogene Research Product, Cambridge, MA, USA) were followed, with some modification. The tissue sections were deparaffinized, rehydrated and rinsed with buffer. They were incubated with proteinase $\mathrm{K}(10 \mu \mathrm{g} / \mathrm{ml})$ at room temperature for $15 \mathrm{~min}$. The endogenous peroxidase was inactivated with $3 \% \mathrm{H}_{2} \mathrm{O}_{2}$ in methanol at room temperature for $10 \mathrm{~min}$. After the tissue sections were rinsed with buffer, they were preincubated with terminal deoxynucleotidyl transferase (TdT) equilibration buffer at room temperature for $30 \mathrm{~min}$, followed with TdT labeling reaction buffer at $4{ }^{\circ} \mathrm{C}$ overnight. After being rinsed with buffer, slides were incubated with blocking buffer for $10 \mathrm{~min}$ and then with the peroxidase streptavidin conjugate. After $30 \mathrm{~min}$, the slides were washed and incubated with 3,3' diaminol benzidine solution for the detection of apoptotic cells. The slides were counterstained with hematoxylin.

Measurement of the thickness and internal circumference of the luminal epithelium

The thickness of the luminal epithelium was measured in four randomly selected areas in a tissue section, using an ocular micrometer. To determine the internal circumference of the lumen, the tissue section was first screened onto the computer at a magnification of $\times 4$ or $\times 10$ under the optical microscope, depending on the size of the lumen. The preprocessed image was then converted to a binary image using the threshold-based image segmentation method. The optimal threshold for dividing the image into foreground and background was computed from the optimization of the between-class variance of the gray-level histogram. The region-growing method was used to fill the vacancy inside the luminal epithelial cells. Finally, the 3'3 Laplacin operator was used to detect the circumference of the luminal epithelium and the internal circumference of the lumen was computed on a pixel-by-pixel basis.

\section{Statistical analysis}

Values are expressed as the means \pm S.E.M. of at least four animals. The statistical significance of differences between respective groups was evaluated by ANOVA followed by Fisher's PLSD test.

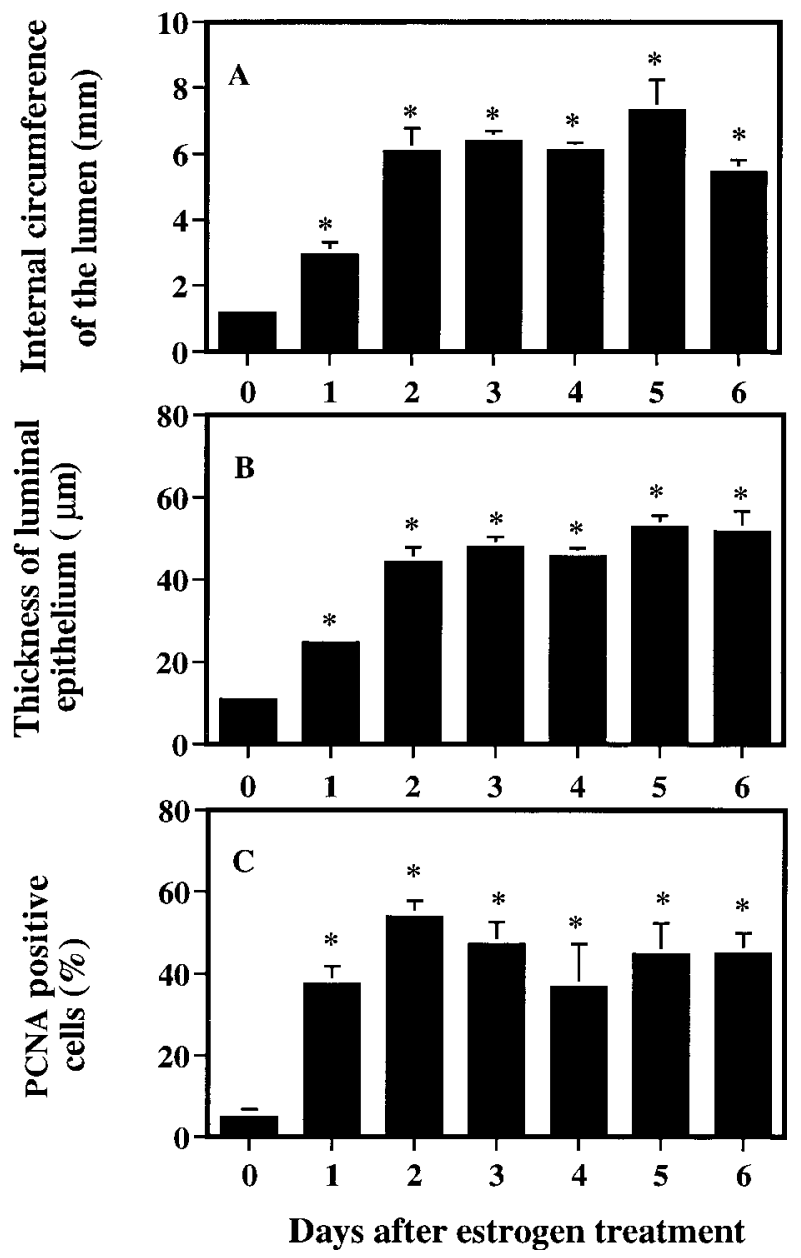

Figure 3 Effect of estrogen on the internal circumference (A), thickness (B) and percentage of PCNA-positive cells (C) in uterine luminal epithelium. Ovariectomized rats were implanted with $E_{2}$ capsules and killed at 0, 1, 2, 3, 4, 5 and 6 days after hormone treatment. ${ }^{*} P<0 \cdot 05$ compared with day 0 .

\section{Results}

We first examined the changes in PCNA expression and apoptotic death during the estrous cycle. As shown in Fig. 1A, there was a strong expression of PCNA in uterine luminal epithelium at the proestrus stage. However, the expression of PCNA diminished at estrus (Fig. 1B) and then increased again at diestrus I and diestrus II (Fig. 1C, D). The appearance of apoptotic cells exhibited a pattern opposite to that for PCNA expression: at proestrus, no dead cells were observed (Fig. 1E); in contrast, dead cells were most prominent at estrus and decreased steadily at diestrus I and II (Fig. 1F-H).

To study further the hormonal control of uterine growth and the expression of PCNA, the estrogen-treated ovariectomized rats were used as a model. Rats were 

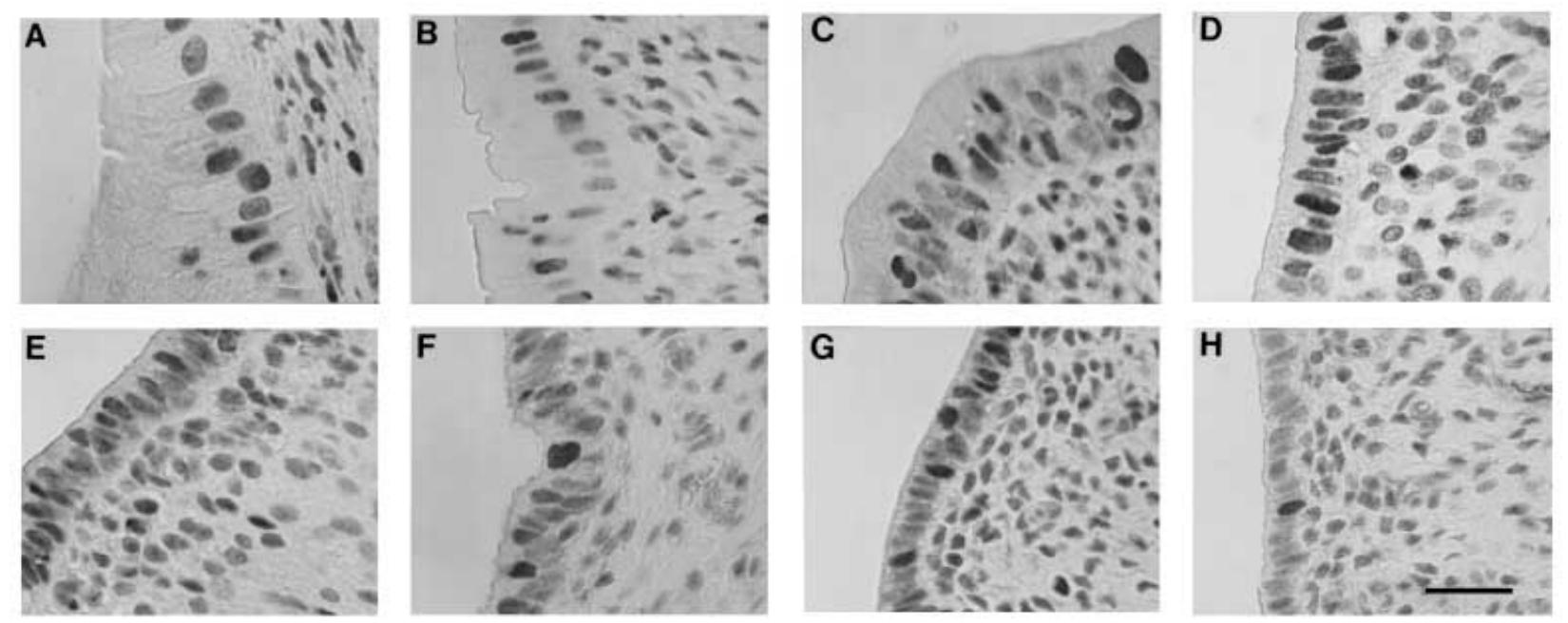

Figure 4 Expression of PCNA after $E_{2}$ withdrawal in the uterine luminal epithelium. Ovariectomized rats were implanted with $E_{2}$ capsules. After 3 days, the capsules were removed; rats were killed at $0(A), 1$ (B), $1.5(C), 2$ (D), 3 (E), 5 (F), 7 (G) and $14(\mathrm{H})$ days after $E_{2}$ removal. Scale bar represents $100 \mathrm{~mm}$.

ovariectomized for at least 2 weeks and then implanted s.c. with a silastic capsule containing $17 \beta$-estradiol. After ovariectomy, there were few PCNA-positive cells in uterine luminal and glandular epithelial cells (Fig. 2A, D). Estrogen treatment stimulated the expression of PCNA in both the luminal and the glandular epithelial cells for 1 (Fig. 2B, E) or 3 days (Fig. 2C, F). As shown in Fig. 3, the percentage of PCNA positive cells increased significantly 1 day after the hormone treatment and remained increased throughout the treatment (Fig. 3C). Both the thickness of the luminal epithelium and the internal circumference of the lumen also increased significantly 1 day after estrogen treatment, reaching a maximal size and maintaining a plateau value through the treatment period (Fig. 3A, B).

To investigate the changes in PCNA during uterine regression after hormone withdrawal, $\mathrm{E}_{2}$ capsules were removed from estrogen-treated ovariectomized rats after 3 days of $E_{2}$ treatment. Expression of PCNA in the luminal epithelium did not decrease during the first 7 days after the removal of estrogen capsules (Fig. 4 A-G). By day 14, only a few scattered PCNA-positive cells were detected (Fig. 4H). As shown in Fig. 5A and B, the internal circumference and thickness of the uterine luminal epithelium decreased significantly by day 1.5 and were reduced to basal values by days 7-14 after removal of the hormone. Meanwhile, the percentage of apoptotic cells peaked at 1.5 days after $\mathrm{E}_{2}$ withdrawal and decreased gradually thereafter (Fig. 5C). Quantitatively, the percentage of PCNA-positive cells did not change in the first 7 days after $\mathrm{E}_{2}$ withdrawal, and during the same period dramatic cell death and tissue regression had occurred in the uterine epithelium. The expression of PCNA diminished significantly by day 14 (Fig. 5D). These results demonstrate that PCNA was expressed in uterine epithelium after estrogen treatment and removal.

\section{Discussion}

The administration and withdrawal of estrogen have been demonstrated to cause uterine growth and regression (Martin et al. 1976, Finn \& Publicover 1984). Expression of PCNA has been reported during uterine growth ( $\mathrm{Li}$ 1994, Tong \& Pollard 1999), but no report has linked the expression of PCNA and uterine regression. Our results clearly show that PCNA expression occurred during growth as expected, but also during the subsequent regression of the uterus.

During the estrous cycle, cyclic proliferation and death of uterine epithelial cells occur. It has been shown that mitosis increased from diestrus toward proestrus, whereas apoptotic death was low at proestrus and increased at estrus (Sandow et al. 1979, Sato et al. 1997). This phenomenon is closely associated with the concentrations of ovarian steroids, which increase from diestrus to proestrus and decrease at estrus (Smith et al. 1975). In this study, our results showed that there was an inverse relationship between the expression of PCNA and apoptosis during the estrous cycle. From diestrus to proestrus, there was strong expression of PCNA in luminal and glandular epithelial cells, but few apoptotic cells. At estrus, when ovarian steroid concentrations decrease, PCNA was not expressed and the appearance of apoptosis was obvious. These observations suggest that the expression of PCNA and mitosis in uterine epithelial cells during the estrous cycle were influenced by ovarian steroids. 


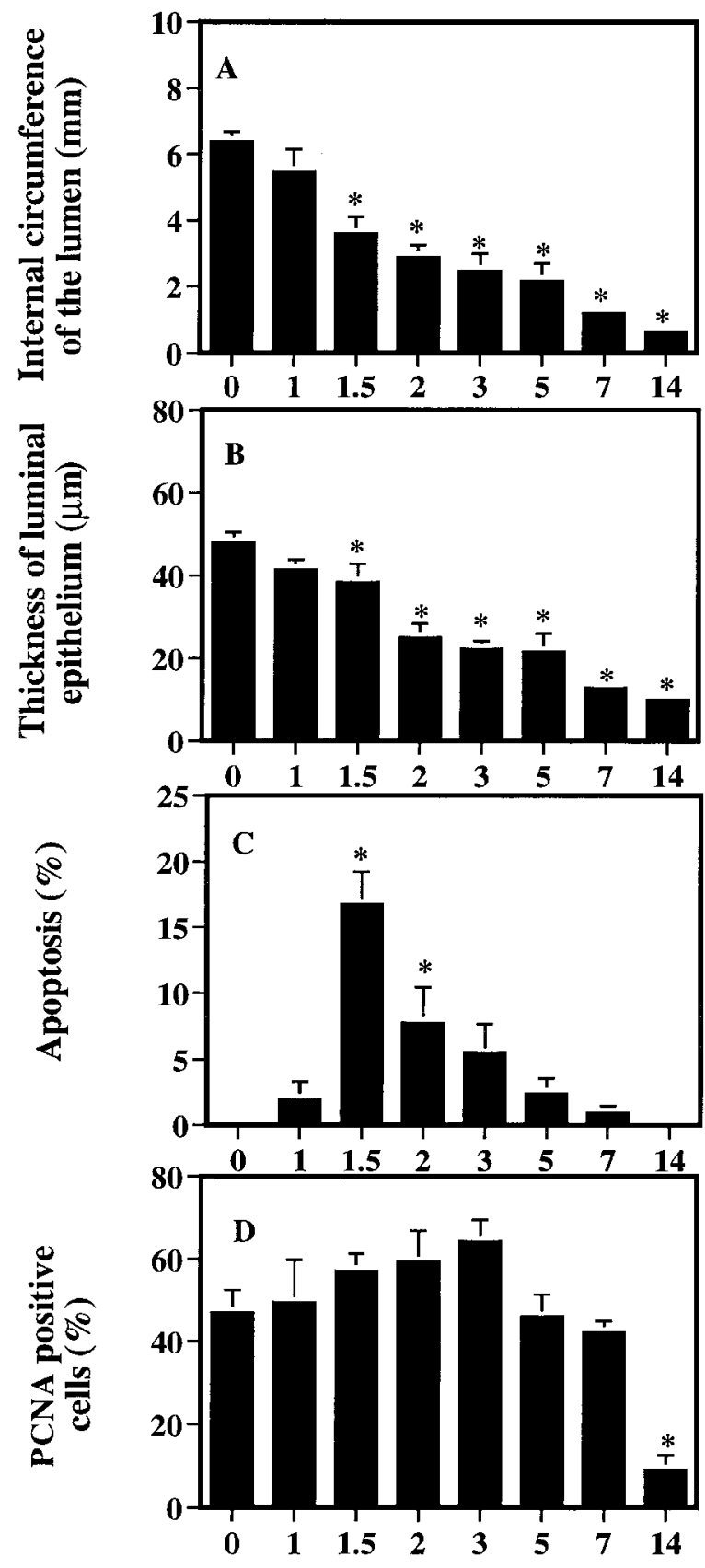

Days after hormonal withdrawal

Figure 5 Changes in the internal circumference (A), thickness (B), apoptotic index (C) and percentage of PCNA-positive cells (D) in uterine luminal epithelium after hormone withdrawal. The day of removing $E_{2}$ capsules is denoted as day 0 . Treatments of the animals were as described in Fig. $4 .{ }^{*} P<0.05$ compared with day 0 .

Estrogen secreted from the ovary during the estrous cycle is the major hormone to stimulate the proliferation of luminal and glandular epithelial cells in the uterus, whereas progesterone inhibits estrogen-induced cell proliferation and causes the cells to differentiate. Using ovariectomized rats supplemented with estrogen alone or in combination with progesterone, Tong \& Pollard (1999) demonstrated that estrogen stimulated the expression of PCNA and DNA synthesis as measured by the incorporation of BrdU in uterine epithelial cells, and that progesterone treatment inhibited both BrdU incorporation and PCNA expression. To simplify the situation, we used ovariectomized rats supplemented with estrogen only in this study. Our results showing that PCNA was expressed strongly in both luminal and glandular epithelial cells after stimulation by estrogen are in good agreement with previous reports. These observations suggest that PCNA can be a good marker for estrogen-stimulated uterine growth.

Much to our surprise we detected a sustained, high level of PCNA expression for 7 days after hormone withdrawal. During this period, the number of apoptotic cells had peaked and decreased to basal values, and regression of the uterus had occurred as indicated by the decreased thickness and internal circumference of the luminal epithelium. The expression of PCNA during tissue atrophy has also been observed in prostate epithelial cells. After castration, prostate epithelial cells underwent apoptosis and exhibited a transient increase in PCNA expression (Colombel et al. 1992). Furthermore, it has been shown that cutaneous burn in mice caused apoptosis in their gut epithelium, atrophy of the tissue being paradoxically associated with an increased expression of PCNA (Wolfe et al. 1999). One plausible explanation for these observations may be provided by the interaction of PCNA with p21 - a cyclindependent kinase inhibitor (Xiong et al. 1993) that is a potent inducer of G1 arrest and can block the onset of DNA replication in response to DNA damage (Gartel et al. 1996). In vitro studies have shown that $\mathrm{p} 21$ mediates the acute inhibition of DNA replication in cells when DNA damage occurs (Li et al. 1994, Shivji et al. 1994, Waga et al. 1994). The interaction between p21 and PCNA may reduce the ability of PCNA to stimulate processive DNA synthesis, hence shifting the balance toward repair-type synthesis of short DNA. If the damage is too severe, apoptosis is likely to occur. It has been reported that exposure of rats to azoxymethanone resulted in apoptosis and inhibition of mitosis in colonic epithelium, with strong expression of PCNA and BrdU detected in damaged cells (Yirose et al. 1996). Thus PCNA expression may not reflect the proliferative state in the early phase after cell damage; instead, a stage of cell cycle arrest or DNA repair is likely to take place. Indeed, in the estrogen-treated mouse model, our current study has shown that the removal of estrogen resulted in a peak of expression of PCNA, accompanied by the incorporation of BrdU but not mitosis (unpublished observations). Although p21 has been detected in human endometrium (Toki et al. 1998), further studies are needed to clarify 
whether $\mathrm{E}_{2}$ withdrawal may induce the expression of $\mathrm{p} 21$, thereby changing the function of PCNA during uterine regression.

The growth of tissues depends not only on the rate of cell proliferation, but also on the rate of cell death. The imbalance of either one would cause abnormal growth or atrophy of the tissues. Therefore, the PCNA labeling index and apoptotic index are often used to assess the status of cell proliferation and death respectively. Our observation of expression of PCNA together with apoptosis during uterine regression indicates that PCNA expression does not necessarily reflect cell proliferation; functions other than cell proliferation should be taken into consideration.

\section{Acknowledgements}

This work was supported by grant NSC86-2314-B006082 from the National Science Council of Taiwan, Republic of China (to L C W). We thank Dr M J Jiang for comments on this manuscript and Mr W H Ding for the technical support of computing analysis.

Parts of these studies were reported at the 32nd Annual Meeting of the Society for the Study of Reproduction, Pullman, WA, USA, August 1999.

\section{References}

Celis JE \& Madsen P 1986 Increased nuclear cyclin/PCNA antigen staining of non S-phase transformed human amnion cells engaged in nucleotide excision DNA repair. FEBS Letters 9 277-283.

Colombel M, Olsson CA \& Buttyan R 1992 Hormone regulated apoptosis results from reentry of differentiated prostate cells onto a defective cell cycle. Cancer Research 52 4313-4319.

Eldridge SR, Butterworth BE \& Goldsworthy TL 1993 Proliferating cell nuclear antigen: a marker for hepatocellular proliferation in rodents. Environmental Health Perspectives 101 (Suppl 5) 211-218.

Finn CA \& Publicover M 1981 Hormonal control of cell death in the luminal epithelium of the mouse uterus. Journal of Endocrinology 91 335-340.

Foley J, Ton T, Maronpot R, Butterworth B \& Goldsworthy TL 1993 Comparison of proliferating cell nuclear antigen to tritiated thymidine as a marker of proliferating hepatocytes in rats. Environmental Health Perspectives 101 (Suppl 5) 199-206.

Gartel AL, Serfas MS \& Tyner AL 1996 p21 - negative regulator of the cell cycle. Proceedings of the Society for Experimental Biology and Medicine 213 138-149.

Kelman Z 1997 PCNA: structure, functions and interactions. Oncogene 14 629-640.

Kelman Z \& Hurwitz J 1998 Protein-PCNA interactions: a DNA-scanning mechanism. Trends in Biochemical Sciences 23 236-238.

Kiya T, Endo T, Goto T, Yamamoto H, Ito E, Kudo R \& Behrman HR 1998 Apoptosis and PCNA expression induced by prolactin in structural involution of the rat corpus luteum. Journal of Endocrinological Investigation 21 276-283.

Legan SJ, Coon GA \& Karsch FJ 1979 Role of estrogen as initiator of daily LH surges in the ovariectomized rat. Endocrinology 96 50-56.
Li S 1994 Relationship between cellular DNA synthesis, PCNA expression and sex steroid hormone receptor status in the developing mouse ovary, uterus and oviduct. Histochemistry 102 405-413.

Li R, Waga S, Hannon GJ, Beach D \& Stillman B 1994 Differential effects by the p21 CDK inhibitor on PCNA-dependent DNA replication and repair. Nature 371 534-537.

Martin L, Pollard JW \& Fagg B 1976 Oestriol, oestradiol-17 $\beta$ and the proliferation and death of uterine cells. Journal of Endocrinology 69 103-115.

Nichols AF \& Sancar A 1992 Purification of PCNA as a nucleotide excision repair protein. Nucleic Acids Research 20 2441-2446.

Quarmby VE \& Korach KS 1984 The influence of $17 \beta$-estradiol on patterns of cell division in the uterus. Endocrinology 114 694-702.

Sandow BA, West NB, Norman RL \& Brenner RM 1979 Hormonal control of apoptosis in hamster uterine luminal epithelium. American Journal of Anatomy 156 15-36.

Sato T, Fukazawa Y, Kojima H, Enari M, Iguchi T \& Ohta Y 1997 Apoptotic cell death during the estrous cycle in the rat uterus and vagina. Anatomical Record 248 76-83.

Shirvan A, Ziv I, Machlin T, Zilkha-Falb R, Melamed E \& Barzilai A 1997 Two waves of cyclin B and proliferating cell nuclear antigen expression during dopamine-triggered neuronal apoptosis. Journal of Neurochemistry 69 539-549.

Shivji MK, Grey SJ, Strausfeld UP, Wood RD \& Blow JJ 1994 CIP1 inhibits DNA replication but not PCNA-dependent nucleotides excision repair. Current Biology 4 1062-1068.

Smith MS, Freeman ME \& Neill JD 1975 The control of progesterone secretion during the estrus cycle and early pseudopregnancy in the rat: prolactin, gonadotropin and steroid levels associated with rescue of the corpus luteum of pseudopregnancy. Endocrinology 96 219-226.

Tasurimoto T 1998 PCNA, a multifunctional ring on DNA. Biochimica et Biophysica Acta 1443 23-39.

Toki T, Mori A, Shimizu M, Nikaido T \& Fujii S 1998 Localization of apoptotic cells within the human endometrium and correlation between apoptosis and p21 expression. Molecular Human Reproduction 4 1157-1164.

Tong W \& Pollard J 1999 Progesterone inhibits estrogen-induced cyclin D1 and cdk4 nuclear translocation, cyclin E- and cyclin A-cdk2 kinase activation, and cell proliferation in uterine epithelial cells in mice. Molecular and Cellular Biology 19 2251-2264.

Toschi L \& Bravo R 1988 Changes in cyclin/proliferating cell nuclear antigen distribution during DNA repair synthesis. Journal of Cell Biology 107 1623-1628.

Waga S, Hannon GJ, Beach D \& Stillman B 1994 The p21 inhibitor of cyclin-dependent kinase controls DNA replication by interacting with PCNA. Nature 369 574-578.

Wolfe SE, Ikeda H, Matin S, Debroy MA, Rajaraman S, Herndon DN \& Thompson JC 1999 Cutaneous burn increases apoptosis in the gut epithelium of mice. Journal of the American College of Surgeons 188 10-16.

Xiong Y, Hannon GJ, Zhang H, Casso D, Kobayashi R \& Beach D 1993 p21 is a universal inhibitor of cyclin kinase. Nature $\mathbf{3 6 6}$ 701-704.

Yirose Y, Yoshimi N, Makita H, Hara A, Tanaka T \& Mori H 1996 Early alterations of apoptosis and cell proliferation in azoxymethaneinitiated rat colonic epithelium. Japanese Journal of Cancer Research $\mathbf{8 7}$ 575-582.

Received 24 November 1999

Accepted 7 March 2000 